\title{
Clone-specific immune reactions in a trematode-crustacean system
}

\author{
ANSON V. KOEHLER* and ROBERT POULIN \\ Department of Zoology, University of Otago, PO Box 56, Dunedin 9054, New Zealand \\ (Received 21 Fune 2011; revised 1 August 2011; accepted 30 August 2011; first published online 14 October 2011)
}

SUMMARY

Variability of immune responses is an essential aspect of ecological immunology, yet how much of this variability is due to differences among parasite genotypes remains unknown. Here, variation in immune response of the crab, Macrophthalmus hirtipes, is examined as a function of experimental exposure to 10 clonal cercarial lineages of the trematode Maritrema novaezealandensis. Our goals were (1) to assess the variability of the host immune reaction elicited by 10 parasite clones, (2) to test if the heterozygosity-fitness correlation, whereby organisms with higher heterozygosities achieve a higher fitness than those with lower heterozygosities, applies to heterozygous parasites eliciting weak immune responses, and (3) to see how concomitant infections by other macroparasites influence the crab's immune response to cercariae. Parasite clones were distinguished and heterozygosities calculated using 20 microsatellite markers. We found that exposure to cercariae resulted in increased haemocyte counts, and that although interclonal differences in immune response elicited were detected, parasite heterozygosity did not correlate with host immune response. Additionally, the presence of other pre-existing parasites in hosts did not influence their immune response following experimental exposure to cercariae. Overall, the existence of variability in immune response elicited by different parasite clones is promising for future ecological immunology studies using this system.

Key words: heterozygosity fitness correlation (HFC), parasite, microsatellite, concomitant infection, total haemocyte count (THC).

\section{INTRODUCTION}

The question of why variation in immune response exists among hosts and the subsequent consequences of this variation are central to the study of evolutionary-ecological immunology (Schmid-Hempel and Ebert, 2003; Rolff and Siva-Jothy, 2003; Sadd and Schmid-Hempel, 2009; Hawley and Altizer, 2010). Schmid-Hempel and Ebert (2003) suggested that the specificity of host responses to different parasite strains is a major component of immune response variation and that this interaction has been underrated in the literature. Knowledge of the parasite's genetic composition is therefore essential to understanding its immunogenicity, or the ability of a parasite to elicit an immune response (Read and Viney, 1996). Only with this knowledge will a more complete picture of the role of immune response variation be achieved.

The ability to effectively discern distinct parasite lineages is thus crucial when trying to correlate host immune response with specific parasite genotypes. There have been earlier studies investigating the host's immune response to several parasite genotypes (reviewed by Lazzaro and Little, 2009). In these studies, methods for determining individual parasite lines have included geographical distinction (Goyal and Wakelin, 1993), microsatellite markers

\footnotetext{
* Corresponding author: Tel: + 64034795848 ; Fax: +6403 479 7584; E-mail: ansonkoehler@gmail.com
}

(Vardo-Zalik, 2009), or multiple laboratory lines (Paterson, 2005; Rauch et al. 2006). More complex studies have used the host genotype by parasite genotype approach to determine whether hosts varied in their susceptibility to distinct parasite genotypes and reciprocally, whether various parasite clones demonstrated different host infectivity (Carius et al. 2001; Seppälä et al. 2009; de Roode and Altizer, 2010). To our knowledge, past studies using microsatellites have relied on only a few markers to differentiate parasite strains (Vardo-Zalik, 2009) and no study has used 20 or more markers to distinguish unique parasite genotypes. The use of multiple microsatellite markers also allows for an estimate of genomic heterozygosity and subsequently the ranking of specific parasites by their degree of heterozygosity. This estimate can be used to investigate heterozygosity-fitness correlations (HFC) (reviewed by Hansson and Westerberg, 2002; Chapman et al. 2009) between the heterozygosity of the pathogen and some component of its fitness. In this case, if the immune response induced in the host varies among parasite genotypes, then it constitutes an aspect of parasite fitness since, all else being equal, those parasite genotypes eliciting weaker immune responses would achieve greater infection success and survival. Based on prior HFC studies, organisms with higher heterozygosities are predicted to have a higher fitness than those with lower heterozygosities (Chapman et al. 2009); although the HFC is rarely tested on parasites, the same prediction should apply. 
In this study the immune response of a decapod crustacean (the ocypodid crab Macrophthalmus hirtipes Jacquinot in Hombron and Jacquinot 1846) when exposed to the cercarial stages of a marine trematode parasite (Maritrema novaezealandensis Martorelli et al. 2004, family Microphallidae) was examined. Trematode parasites are ideal candidates for studying immune response variation among single-genotype infections, and subsequently the role of parasite heterozygosity in host response. Trematodes multiply asexually within a snail intermediate host, producing extensive numbers of dispersal stages (known as cercariae), all genetically identical replicates (clones) of the original larva that infected the snail. In $M$. novaezealandensis, cercariae leave the snail to penetrate any of a range of crustacean species serving as second intermediate hosts, in which they encyst as metacercariae (Koehler and Poulin, 2010). When an invading particle such as a cercaria penetrates a crustacean, an innate immune response is triggered via the haemolymph inducing both cellular and humoral responses (Jiravanichpaisal et al. 2006). The cellular response involves phagocytosis, aggregation, or encapsulation of the particle by haemocytes, which are found circulating in the haemolymph (Jiravanichpaisal et al. 2006). The humoral response is closely tied to the cellular response as haemocytes contain the molecules responsible for inducing the pro-phenoloxidase (pro-PO) cascade, which melanises the cercariae (Söderhäll and Cerenius, 1998; Jiravanichpaisal et al. 2006). The present study concentrates on the cellular response.

Using experimental infections of crabs by $M$. novaezealandensis, the goals of this study were 3 -fold. First, the variability of immune reactions, measured as total haemocyte counts, induced in the host among 10 clonal parasites was assessed. Second, we tested whether or not parasites with higher heterozygosities demonstrate a higher fitness, estimated here as being inversely proportional to the immune response they elicit. It was predicted that either (a) high heterozygosity clones will be more adept at evading host defences by triggering a reduced immune response compared to the low heterozygosity clones, or (b) assuming equal immune responses are triggered by all clones, high heterozygosity clones should be more successful at evading the response. This study investigated the former scenario. Third, we determined how the presence of pre-existing parasite infections in the crabs (other than the trematode $M$. novaezealandensis) influenced their immune response.

\section{MATERIALS AND METHODS}

\section{Parasite collection}

Zeacumantus subcarinatus (Sowerby 1855) snails (first intermediate hosts of Maritrema novaezealandensis) were collected on 4 July 2010 from Company Bay, Otago Harbour, Dunedin, New Zealand (45 $51^{\prime}$ $23.8^{\prime \prime} \mathrm{S}, 170^{\circ} 35^{\prime} 54.3^{\prime \prime} \mathrm{E}$ ). To screen them for the presence of $M$. novaezealandensis, 1368 snails were placed individually into 12 -well polystyrene plates filled with $5 \mathrm{ml}$ of seawater. Snails were then exposed to the conditions that promote cercarial shedding $\left(25^{\circ} \mathrm{C}\right.$ under bright light for $3 \mathrm{~h}$; Fredensborg et al. 2004) and 73 snails (5·3\%), from which microphallid cercariae were released, were found. Snails were measured to the nearest $0 \cdot 1 \mathrm{~mm}$ with Vernier calipers from the base of the aperture to the apex (Hay et al. 2005) and individually marked using cyanoacrylate glue and numbered plastic tags (Bee Works, Orillia, ON, Canada). Infected snails were held in captivity for approximately 3 months prior to experimental infections, in a $40 \mathrm{~L}$ aquarium containing an autoclaved mixture of fine sand collected from Lower Portobello Bay, Otago Harbour. Captive snails were fed ad libitum with sea lettuce (Ulva spp.) collected from Otago Harbour. Water in the aquarium was maintained at approximately $19^{\circ} \mathrm{C}$ using an aquarium heater, aerated and replaced with fresh seawater from Otago Harbour once a month. Light was supplied through full UV spectrum light bulbs set on a $12 \mathrm{~h}$ cycle (Sylvania GroLux F36W/T8, Germany).

\section{Genotyping}

To verify that each experimental snail was only infected by $M$. novaezealandensis and by a single clone of that species, cercarial shedding was stimulated on 3 occasions, their DNA extracted using Chelex (Walsh et al. 1991) and pooled, and their mitochondrial cytochrome oxidase I genes were sequenced and compared (methods detailed by Koehler et al. 2011b). No parasites other than $M$. novaezealandensis were detected. Then, snails infected with multiple clones of $M$. novaezealandensis were ruled out and genome-wide heterozygosity (percentage of heterozygous loci) was estimated by a genotyping method modified from Schuelke (2000) and Hayden et al. (2008) involving multiplexes of 4 fluorescent dyes (NED, FAM, VIC and PET (Applied Biosystems)) and 4 product sizes. Thirty-one previously reported $M$. novaezealandensis microsatellite primers (Keeney et al. 2006; Molecular Ecology Resources Primer Development Consortium, 2009) were altered by adding M13 (-21) tags ('TGTAAAACGACGGCCAGT) to the 5' end of each primer (Schuelke, 2000) and a pigtail (GTTTCTT) (Brownstein et al. 1996) to the $5^{\prime}$ end of each reverse primer. Each primer was assigned to one of two plates (provided in Appendix 1). Some primers were also altered to accommodate the 4 size classes. After these alterations, 20 of the 31 primers successfully amplified microsatellite regions (Appendix 1). For each of the 20 primer pairs, a PCR was performed on the 73 parasite extractions see 
Schuelke (2000) for PCR reaction concentrations and conditions. For both groups of primers, $2 \mu \mathrm{l}$ of PCR product were diluted 1:20 with $\mathrm{dH}_{2} 0$. These were run on a 3730XL DNA Analyser machine (Applied Biosystems). Results were interpreted using the program GeneMapper v 3.7 (Applied Biosystems).

\section{Experimental infections}

Host collection. A previous study on immune reaction of the crabs Macrophthalmus hirtipes and Hemigrapsus crenulatus (H. Milne-Edwards 1837) when exposed to $M$. novaezealandensis, found that $M$. hirtipes had a greater, more pronounced immune reaction compared to $H$. crenulatus (Dittmer, 2010); therefore $M$. hirtipes was selected for this study. Female $M$. hirtipes crabs $(N=240)$ of similar size (mean carapace width $=15.6 \mathrm{~mm} \pm 1.44$ s.D. $)$ and reproductive status (non egg-bearing) were collected from Taieri River Mouth, Otago, New Zealand $\left(46^{\circ}\right.$ $3^{\prime} 3.0^{\prime \prime} \mathrm{S}, 170^{\circ} 11^{\prime} 24.2^{\prime \prime} \mathrm{E}$ ) on 13 September 2010. This site was chosen because it has a high abundance of crabs, generally lower parasite densities than other neighbouring localities, and lacks the snail $Z$. subcarinatus, an important intermediate host for several trematodes in addition to $M$. novaezealandensis (Dittmer, 2010; Dittmer et al. 2011; A. Koehler, unpublished observations). Parasite-naïve crabs would have been preferred for this study; however, the culturing of crabs in a sterile environment from eggs to an age where they can be infected was not a feasible option.

Infection procedures. Crabs were divided up and housed in twenty $2 \mathrm{~L}$ plastic containers filled with $1 \mathrm{~L}$ of aerated seawater, fed Ulva spp. ad libitum, and maintained at approximately $12{ }^{\circ} \mathrm{C}$. They were allowed to acclimate to their surroundings for 5 days prior to the first infections. In total, 10 trematode clones (5 with the highest heterozygosity and 5 with the lowest heterozygosity) were used to infect 20 crabs each. Infections were conducted over a 5 -day period. On days 1, 3, 4, and 5 of infection, 10 control crabs that received no cercariae (shaminfected) were also included in the trial, for a total of 40 control individuals. Infections were conducted as outlined below. Crabs were contained in plastic Petri dishes ( $35 \mathrm{~mm}$ diameter by $10 \mathrm{~mm}$ height) filled with $1 \mathrm{ml}$ of seawater. These small containers prevented any avoidance behaviour by the crabs when exposed to cercariae by confining their movements. Cercariae were added through a hole that had been drilled into the lid of the Petri dish, with a rubber band securing the lid. As before, snails were induced to shed cercariae at $25^{\circ} \mathrm{C}$ and 50 cercariae of a given clone were transferred, using a $0 \cdot 5-10 \mu \mathrm{l}$ pipette, to each Petri dish containing a crab. Crabs were kept at $24^{\circ} \mathrm{C}$ for $5 \mathrm{~h}$ (incubation conditions adapted from Fredensborg et al. (2004)) to ensure that infections took place. Crabs were then transferred from their Petri dishes to $2 \mathrm{~L}$ white plastic containers filled with seawater and placed in an incubator set to $20^{\circ} \mathrm{C}$ for $48 \mathrm{~h}$.

Haemolymph analysis. The immune responses of invertebrates can be measured using several methods including total haemocyte counts (THC) and circulating levels of the pro-PO molecules in the haemolymph. The use of THC to assess immunological responses was scrutinized by Söderhäll et al. (2003) and Kurtz (2002) because of the documented extent of variation in THC among individual hosts. However, when sources of variation are taken into account and results are treated with caution, this method still provides useful insights into immunity. Kurtz (2002) identified host developmental stage, age, gender, reproductive stage, and environment (i.e., food, stress, activity, temperature, salinity, $\mathrm{pH}$, and $\mathrm{O}_{2}$ levels) as potential sources of variation. Here, each of these factors is addressed by using only non eggbearing female crabs of similar size (age class) collected from the same locality, on the same day and maintained under identical conditions while in captivity. A prior study of host-parasite immune reaction in the same system found that THC were more reliable than pro-PO levels (Dittmer, 2010), justifying the present choice of THC to measure the immune response. Nevertheless, there is no consensus regarding what post-infection THC should be. Some studies, including one using the same crab and parasite species used in this study (Dittmer, 2010), found increased THC levels. The inclusion of appropriate controls to obtain suitable baseline measures is thus essential.

At the end of the 48-h period, each crab's rear pereopods were removed and $4 \mu \mathrm{l}$ of haemolymph were collected and added to $8 \mu \mathrm{l}$ of the anticoagulant Modified Alsever Solution (MAS) $(366 \mathrm{~mm} \mathrm{NaCl}$, 9 mм EDTA, 115 mm glucose, 27 mm sodium citrate, pH 7·4 (Rodriguez et al. 1995)), and $4 \mu$ l of Trypan Blue dye $(0.4 \%$ aqueous $)$ used to stain dead cells (Sicard et al. 2010). Fifteen microlitres of this mixture were then pipetted onto a haemacytometer (Hawksley, Lancing, England) where 10 rows were counted and extrapolated to give the number of haemocytes $/ \mathrm{ml}$ of haemolymph. Dead haemocytes, stained blue, were ignored. Counts were made by a single observer to minimize variability.

Dissections. Crabs were killed by first placing them in a $-20{ }^{\circ} \mathrm{C}$ freezer for $8 \mathrm{~min}$ followed by severing their ventral nerve cords. All tissues in each crab were thoroughly examined for macroparasites (nematodes, trematodes, acanthocephalans and parasitic isopods). Pre-existing parasites within crabs were unavoidable, although we chose a locality with low parasite loads compared to surrounding areas. In other ecological 
Table 1. Summary data on heterozygosity (HZ), average total haemocyte counts (THC), and host size associated with clones of the parasite Maritrema novaezealandensis in experimental infections of the host Macrophthalmus hirtipes

\begin{tabular}{|c|c|c|c|c|c|}
\hline Clone & $\mathrm{HZ}$ & HZ level & $\begin{array}{l}\text { Haemocytes/ml } \\
\text { (THC) }\end{array}$ & $\begin{array}{l}\text { No. of } \\
\text { crabs }\end{array}$ & $\begin{array}{l}\text { Average carapace } \\
\text { width } \mathrm{mm}( \pm \text { S.E. })\end{array}$ \\
\hline $\mathrm{A}$ & $0 \cdot 20$ & Low & $5 \cdot 57 \times 10^{6}$ & 20 & $16 \cdot 3( \pm 0 \cdot 28)$ \\
\hline $\mathrm{B}$ & $0 \cdot 25$ & Low & $4.92 \times 10^{6}$ & 14 & $15 \cdot 1( \pm 0 \cdot 30)$ \\
\hline $\mathrm{C}$ & $0 \cdot 30$ & Low & $6 \cdot 48 \times 10^{6}$ & 20 & $15 \cdot 3( \pm 0 \cdot 32)$ \\
\hline $\mathrm{D}$ & $0 \cdot 32$ & Low & $6 \cdot 16 \times 10^{6}$ & 20 & $16 \cdot 0( \pm 0 \cdot 32)$ \\
\hline $\mathrm{E}$ & $0 \cdot 35$ & Low & $4 \cdot 28 \times 10^{6}$ & 20 & $15 \cdot 0( \pm 0 \cdot 40)$ \\
\hline $\mathrm{F}$ & 0.58 & High & $5 \cdot 53 \times 10^{6}$ & 20 & $15 \cdot 5( \pm 0 \cdot 34)$ \\
\hline G & 0.58 & High & $4.58 \times 10^{6}$ & 20 & $15 \cdot 4( \pm 0 \cdot 28)$ \\
\hline $\mathrm{H}$ & $0 \cdot 60$ & High & $6 \cdot 25 \times 10^{6}$ & 20 & $15 \cdot 1( \pm 0 \cdot 26)$ \\
\hline I & $0 \cdot 63$ & High & $4.50 \times 10^{6}$ & 20 & $16 \cdot 0( \pm 0 \cdot 27)$ \\
\hline $\mathrm{J}$ & $0 \cdot 63$ & High & $5 \cdot 23 \times 10^{6}$ & 20 & $15 \cdot 8( \pm 0 \cdot 22)$ \\
\hline Control & NA & $\mathrm{NA}$ & $4 \cdot 25 \times 10^{6}$ & 40 & $15 \cdot 9( \pm 0 \cdot 27)$ \\
\hline
\end{tabular}

systems, concomitant infections can either increase immune reactions or suppress them (Cox, 2001). Therefore an attempt was made to control for immune responses elicited by pre-existing parasites by including them as factors in the regression outlined below. Parasite prevalence and mean intensity (total number of parasites divided by the total number of infected hosts) were computed for each parasite species. The same observer performed all dissections.

\section{Statistical analysis}

Analyses were performed using the statistical program R v2.11.1 (R Development core team, 2010). When appropriate, data were Box-Cox transformed to meet assumptions of normality and homogeneity of variances. A one-way ANOVA was performed to detect differences among parasite clones (and versus sham-infected control crabs) in the host immune response they elicited, measured as haemocyte count. A multiple linear regression was used to assess the respective influence of crab size, heterozygosity level of the trematode clone, and numbers of each preexisting parasite species on haemocyte counts among individual crabs; control crabs were excluded, i.e. the multiple regression included only crabs exposed to M. novaezealandensis. Clone identity itself could not be added to the multiple regression because of collinearity with heterozygosity.

\section{RESULTS}

The Average Total Haemocyte Counts (THC) per individual crab ranged from $4 \cdot 25 \times 10^{6}$ for the control group to $6.48 \times 10^{6}$ for crabs exposed to clone ' $\mathrm{C}$ ' (Table 1); therefore, all groups of exposed crabs showed higher THC than control crabs, by up to about $50 \%$ in some cases. Indeed, the one-way ANOVA shows a significant difference in haemocyte levels among groups, more specifically between some of the clones and the control group $\left(F_{10,223}=1 \cdot 885\right.$,

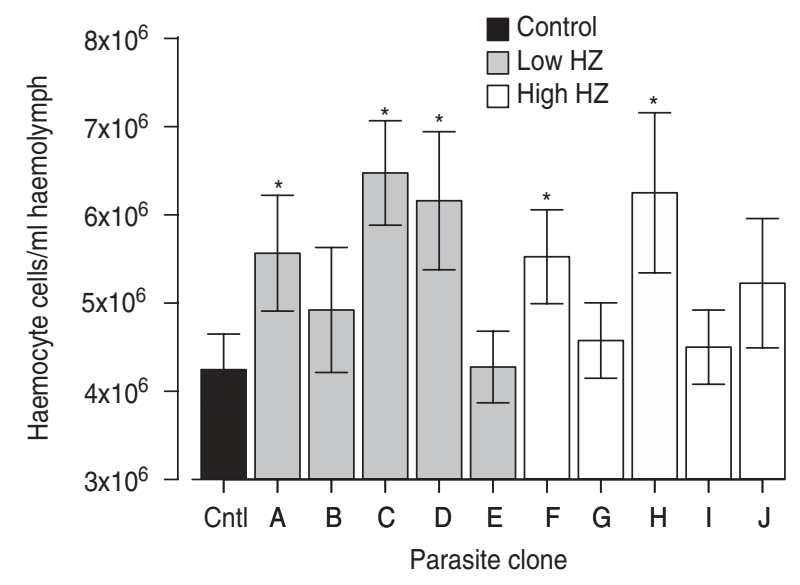

Fig. 1. Average total haemocyte count (THC) of the host, Macrophthalmus hirtipes, when exposed to 50 Maritrema novaezealandensis cercariae from 5 low heterozygosity clones (Low HZ) and 5 high heterozygosity clones (High $\mathrm{HZ}$ ), and values for an unexposed control group. Asterisks (*) indicate which clones have THCs significantly different from the control group $(P<0 \cdot 05)$. Error bars $=$ s.E.

$P=0.048) \quad($ Fig. 1). Heterozygosities of the M. novaezealandensis clones from 73 infected snails, at 20 microsatellite loci, ranged from $20 \cdot 0 \%$ to $63 \cdot 2 \%$ with an average of $46 \cdot 7 \% \pm 1 \cdot 2$ (Table 1 ).

The dissections revealed that pre-existing parasites were abundant. Acuariid nematodes were the most common parasites found in the crabs, followed by the acanthocephalan Profilicollis spp. and an unidentified zoogonid trematode, while the nematode Ascarophis sp. and the parasitic isopod Portunion sp. were more rare (Table 2). The multiple linear regression shows that none of these pre-existing parasites had a significant influence on immune variation among crabs ('Table 3). Further, crab size and heterozygosity level of the $M$. novaezealandensis clone to which they were exposed also did not significantly influence variation in immune response (haemocyte count, THC) among exposed crabs (Table 3). 
Table 2. Prevalence and mean intensity (in parentheses, \pm s.e.) of pre-existing parasites found in the crabs infected by each of the Maritrema novaezealandensis clones and in control crabs

\begin{tabular}{llllll}
\hline \hline Clone & $\begin{array}{l}\text { Profilicollis spp. } \\
\text { Acanthocephalan }\end{array}$ & $\begin{array}{l}\text { Ascarophis sp. } \\
\text { Nematode }\end{array}$ & $\begin{array}{l}\text { Acuariid } \\
\text { Nematode }\end{array}$ & $\begin{array}{l}\text { Zoogonid } \\
\text { Trematode }\end{array}$ & $\begin{array}{l}\text { Portunion sp. } \\
\text { Isopod }\end{array}$ \\
\hline A & $0 \cdot 40(2 \cdot 3 \pm 0 \cdot 6)$ & $0 \cdot 05(\mathrm{na})$ & $1 \cdot 00(13 \cdot 7 \pm 2 \cdot 5)$ & $0 \cdot 20(20 \cdot 3 \pm 17 \cdot 9)$ & 0 \\
B & $0 \cdot 29(1 \cdot 0 \pm$ na) & $0 \cdot 07(\mathrm{na})$ & $0 \cdot 64(2 \cdot 8 \pm 0 \cdot 9)$ & $0 \cdot 50(34 \cdot 4 \pm 16 \cdot 3)$ & 0 \\
C & $0 \cdot 55(1 \cdot 6 \pm 0 \cdot 3)$ & $0 \cdot 05(\mathrm{na})$ & $1 \cdot 00(7 \cdot 6 \pm 1 \cdot 5)$ & $0 \cdot 35(19 \cdot 0 \pm 10 \cdot 9)$ & 0 \\
D & $0 \cdot 55(2 \cdot 6 \pm 1 \cdot 0)$ & $0 \cdot 15(1 \cdot 3 \pm 0 \cdot 3)$ & $1 \cdot 00(6 \cdot 0 \pm 0 \cdot 9)$ & $0 \cdot 40(18 \cdot 1 \pm 6 \cdot 8)$ & 0 \\
E & $0 \cdot 30(4 \cdot 3 \pm 2 \cdot 0)$ & $0 \cdot 05(\mathrm{na})$ & $0 \cdot 85(6 \cdot 9 \pm 1 \cdot 9)$ & $0 \cdot 25(17 \cdot 2 \pm 8 \cdot 9)$ & 0 \\
F & $0 \cdot 30(1 \cdot 7 \pm 0 \cdot 5)$ & 0 & $1 \cdot 00(7 \cdot 5 \pm 0 \cdot 9)$ & $0 \cdot 30(21 \cdot 0 \pm 9 \cdot 3)$ & $0 \cdot 05(\mathrm{na})$ \\
G & $0 \cdot 45(3 \cdot 2 \pm 1 \cdot 7)$ & $0 \cdot 05(\mathrm{na})$ & $1 \cdot 00(7 \cdot 3 \pm 1 \cdot 5)$ & $0 \cdot 25(31 \cdot 0 \pm 8 \cdot 5)$ & 0 \\
H & $0 \cdot 45(1 \cdot 8 \pm 0 \cdot 5)$ & $0 \cdot 05(\mathrm{na})$ & $0 \cdot 95(6 \cdot 6 \pm 1 \cdot 1)$ & $0 \cdot 40(9 \cdot 1 \pm 3 \cdot 8)$ & 0 \\
I & $0 \cdot 55(1 \cdot 6 \pm 0 \cdot 3)$ & $0 \cdot 10(1 \pm \mathrm{na})$ & $0 \cdot 95(10 \cdot 8 \pm 2 \cdot 6)$ & $0 \cdot 35(28 \cdot 3 \pm 6 \cdot 7)$ & 0 \\
J & $0 \cdot 30(2 \cdot 7 \pm 0 \cdot 8)$ & $0 \cdot 10(1 \pm \mathrm{na})$ & $1 \cdot 00(7 \cdot 5 \pm 1 \cdot 3)$ & $0 \cdot 20(13 \cdot 5 \pm 8 \cdot 1)$ & 0 \\
Control & $0 \cdot 48(2 \cdot 4 \pm 0 \cdot 6)$ & $0 \cdot 03(\mathrm{na})$ & $1 \cdot 00(15 \cdot 9 \pm 2 \cdot 4)$ & $0 \cdot 60(22 \cdot 2 \pm 4 \cdot 8)$ & $0 \cdot 03(\mathrm{na})$ \\
\hline \hline
\end{tabular}

Table 3. Summary of multiple linear regression with haemocyte count as the response variable and crab size, heterozygosity (HZ) level (high or low) of the Maritrema novaezealandensis clone used, and pre-existing numbers of other parasites as predictor variables

\begin{tabular}{lrrrc}
\hline \hline Predictor & $\begin{array}{l}\text { Coefficient } \\
\text { estimate }\end{array}$ & \multicolumn{1}{c}{ s.E. } & $t$ value & $P$ value \\
\hline (Intercept) & $119 \cdot 57$ & $14 \cdot 19$ & $8 \cdot 428$ & $<0 \cdot 0001$ \\
Crab size & -1.37 & 0.94 & $-1 \cdot 455$ & $0 \cdot 147$ \\
HZ level & $1 \cdot 89$ & $2 \cdot 32$ & $0 \cdot 812$ & $0 \cdot 418$ \\
Profilicollis & $0 \cdot 09$ & 0.58 & $0 \cdot 15$ & $0 \cdot 881$ \\
Ascarophis & $4 \cdot 20$ & $3 \cdot 86$ & $1 \cdot 09$ & $0 \cdot 277$ \\
Acuariid & -0.03 & $0 \cdot 17$ & $-0 \cdot 173$ & $0 \cdot 863$ \\
Zoogonid & $0 \cdot 04$ & $0 \cdot 07$ & $0 \cdot 553$ & $0 \cdot 581$ \\
Portunion & 3.59 & $16 \cdot 19$ & $0 \cdot 222$ & $0 \cdot 825$ \\
\hline \hline
\end{tabular}

DISCUSSION

The goals of this study were to assess the variability of immune reaction among crabs exposed to the 10 Maritrema novaezealandensis clones, to test whether the HFC hypothesis predicting an association between immune reaction and 2 levels of parasite heterozygosity is supported in this system, and to see how the presence of other pre-existing parasites influences the immune response. With variability in host developmental stage, age, gender, reproductive stage, and environment excluded from the experiment, we found that immune reaction varied among the crab hosts exposed to the 10 different parasite clones. All parasite clones elicited an increase in haemocyte counts, although no relationship was found between either parasite heterozygosity and host immune response, or infection by pre-existing parasites and immune response.

\section{Variability of immune response among clones}

The increase in THC following exposure to parasites agrees with results from a previous study on this system (Dittmer, 2010) and several other studies that have examined post-exposure invertebrate THC levels (Nappi, 1981; Sequeira et al. 1996; Eslin and Prévost, 1998; Kraaijeveld et al. 2001). However, the increase observed here contrasts with other studies showing a decrease in THC (Hillyer et al. 2005; Cornet et al. 2009) and still others showing an initial decrease followed by a return to prior levels (Persson et al. 1987; Lorenzon et al. 1999). This discrepancy can be attributed to a number of possible factors. Haemocytes are produced by haematopoietic tissue and are released into the haemolymph via unknown mechanisms (Jiravanichpaisal et al. 2006). Most of the studies measuring haemocyte counts in crustaceans involve bacterial and viral pathogens as these are of most concern to the aquaculture industry (Jiravanichpaisal et al. 2006), yet these studies using microparasites might not be comparable to the current study where relatively large cercariae serve as the invading pathogen. The timing of the THC may also contribute to the observation of either an increase or decrease in counts. Several studies performed counts within minutes to hours post-exposure and found immediate decreases in THC (Persson et al. 1987; Lorenzon et al. 1999). One study that used acanthocephalans and isopods included a period of several weeks post-exposure before measurement of THC and found an overall decrease, which could be attributed to declining host health (Cornet et al. 2009). In the current study, counts were only taken after a period of $48 \mathrm{~h}$ to allow for the cercariae to penetrate the host and migrate into the haemolymph. At that time, THC counts in crabs exposed to cercariae were consistently higher than in control crabs, with different parasite clones eliciting THC increases of different magnitudes.

\section{Heterozygosity fitness correlation and immune response}

The current study attempted to see if the heterozygosity of the parasite influenced the immune response elicited in the host, as an extension of the general heterozygosity-fitness correlation (Chapman 
et al. 2009) that suggests organisms with higher heterozygosities have higher fitness levels. An earlier study on Maritrema novaezealandensis (Koehler et al. 2011a) found that infection success was significantly greater for clones with low heterozygosity than those with high heterozygosity in one amphipod host, but not in a different amphipod species. Another study (Koehler et al. 2011b) on M. novaezealandensis found no relationship between clone heterozygosity and various phenotypic measurements of the cercariae that may relate to infection success. The results herein do not support the hypothesis that parasites with higher heterozygosities achieve a higher fitness by eliciting lower immune responses. This expectation was based on the assumption that clones possessing high heterozygosities would be more adept at evading immune responses than low-heterozygosity clones. Instead, no significant difference in the crab immune response elicited by parasite clones with high and low heterozygosities was found. These results concern only the cellular immune response, and it is possible that a different pattern applies to the humoral response involving melanization of invading pathogens. Evidence of differential immune reactions, where some cercariae or other helminth larvae are melanized and others not, has been reported for a number of host/parasite associations (Thomas et al. 1995, 2000; Le Moullac and Hafner, 2000; Rigaud and Moret, 2003; Kostadinova and Mavrodieva, 2005). Partial melanization is also seen with $M$.novaezealandensis in multiple crustacean host species (Bryan-Walker et al. 2007; Koehler and Poulin, 2010). No studies have used single genotype infections to determine whether certain parasite strains are more susceptible to melanization than others. However, Seppälä et al. (2007) exposed cercariae (presumably from single-genotype infections) to fish and found variable infectivity suggesting a genetic basis for this variability. Based on the results from this study, the heterozygosity-fitness correlation does not help to explain the variation. If immune variability does have a genetic basis, genome-wide heterozygosity may not be reflective of potential genes that are actually involved in the parasite's immune evasion. Although Dittmer (2010) measured the proPO enzyme cascade involved in melanization and found it much less responsive to trematode infections compared to THC, additional attempts at using methods to quantify pro-PO should be considered in future studies.

\section{Concomitant parasitic infections and immune response}

Pre-existing parasite infections did not influence the host's immune reaction to experimental exposure to $M$. novaezealandensis, a finding that supports the results of Dittmer (2010). Interspecific interactions between parasites that infect hosts with pre-established infections have been shown to either increase infectivity (from depleted host immune responses) or decrease infectivity (through resource competition or elevated host immune responses) (Seppälä et al. 2009). However, the majority of studies investigating concomitant parasite infections have involved vertebrate immune systems (Cox, 2001; Bordes and Morand, 2009; Seppälä et al. 2009) which, given adaptive immunity, are more complex and not comparable to invertebrate immune systems. Studies focused on invertebrates typically involve interactions between helminths and microparasites such as protozoa, bacteria or viruses and rarely interactions among helminths (Thomas et al. 2003). In this study, M. novaezealandensis was the only parasite with an experimentally controlled infection intensity level, as all other parasites were from wild infections. Because parasite-naïve crabs were not used we cannot rule out the possibility that the pre-existing parasites had altered the crab's immune system prior to infection with $M$. novaezealandensis. Inferences from experimentally controlled studies provide solid evidence whereas studies using natural infections provide only circumstantial evidence (Poulin, 2001).

In summary, immune responses were successfully induced in crabs by exposure to cercariae, there were interclonal differences among the parasites in immune response elicited, haemocyte counts in exposed crabs did not correlate with parasite heterozygosity, and there was no evidence that the presence of other parasite species in the hosts influenced their immune response to newly-acquired cercariae. Future studies could benefit from using different measures of immunity. It may also be informative to allow infections to reach the metacercarial stage in the crustacean host, to enable the proper measurement of infection success. In addition, it would be interesting to see how immune responses vary among multiple host species with differing capacities of melanization. Finally, the use of a host-parasite system with a parthenogenetic crustacean host such as the Marmorkrebs crayfish (Scholtz et al. 2003) would allow for more sophisticated host-genotype X parasite-genotype experimental designs. All these would be promising ways to build on the present results demonstrating interclonal (i.e. genetic) differences in the magnitude of immune responses elicited by parasites in their crustacean hosts.

\section{ACKNOWLEDGEMENTS}

We thank L. Kremer, J. Nelles, J. Dittmer, K. Judge, T. King, and S. Townsend for technical assistance and advice. We thank B. Presswell for comments on an earlier draft of this manuscript.

FINANCIAL SUPPORT

This project was funded by a Marsden Fund (Royal Society of New Zealand) grant awarded to R.P. and Devon Keeney. 


\section{REFERENCES}

Bordes, F. and Morand, S. (2009). Coevolution between multiple helminth infestations and basal immune investment in mammals: cumulative effects of polyparasitism? Parasitology Research 106, 33-37.

Brownstein, M. J., Carpten, J. D. and Smith, J. R. (1996). Modulation of non-templated nucleotide addition by tag DNA polymerase: Primer modifications that facilitate genotyping. BioTechniques 20, 1004-1010.

Bryan-Walker, K., Leung, T.L.F. and Poulin, R. (2007). Local adaptation of immunity against a trematode parasite in marine amphipod populations. Marine Biology 152, 687-695.

Carius, H. J., Little, T. J. and Ebert, D. (2001). Genetic variation in a hostparasite association: Potential for coevolution and frequency-dependent selection. Evolution 55, 1136-1145.

Chapman, J. R., Nakagawa, S., Coltman, D. W., Slate, J. and Sheldon, B.C. (2009). A quantitative review of heterozygosity-fitness correlations in animal populations. Molecular Ecology 18, 2746-2765. Cornet, S., Franceschi, N., Bauer, A., Rigaud, T. and Moret, Y. (2009) Immune depression induced by acanthocephalan parasites in their intermediate crustacean host: Consequences for the risk of super-infection and links with host behavioural manipulation. International fournal for Parasitology 39, 221-229.

Cox, F.E. G. (2001). Concomitant infections, parasites and immune responses. Parasitology 122 (Suppl.) S23-38.

de Roode, J. C. and Altizer, S. (2010). Host-parasite genetic interactions and virulence transmission relationships in natural populations of monarch butterflies. Evolution 64, 502-514.

Dittmer, J. (2010). The influence of parasites as an environmental factor on the immune response and haemolymph bacterial loads in New Zealand shore crabs. Unpublished Master's thesis. Université de Poitiers, Poitiers, France.

Dittmer, J., Koehler, A. V., Richard, F., Poulin, R. and Sicard, M. (2011). Parasitic pressure as a source of immune variation among populations of New Zealand shore crabs. Parasitology Research 109 759-767.

Eslin, P. and Prévost, G. (1998). Hemocyte load and immune resistance to Asobara tabida are correlated in species of the Drosophila melanogaster subgroup. Fournal of Insect Physiology 44, 807-816.

Fredensborg, B. L., Mouritsen, K. N. and Poulin, R. (2004). Intensitydependent mortality of Paracalliope novizealandiae (Amphipoda

Crustacea) infected by a trematode: experimental infections and field observations. Fournal of Experimental Marine Biology and Ecology 311, 253 265 .

Goyal, P. K. and Wakelin, D. (1993). Influence of variation in host strain and parasite isolate on inflammatory and antibody responses to Trichinella spiralis in mice. Parasitology 106, 371-378

Hansson, B. and Westerberg, L. (2002). On the correlation between heterozygosity and fitness in natural populations. Molecular Ecology $\mathbf{1 1}$ 2467-2474.

Hawley, D. M. and Altizer, S. M. (2010). Disease ecology meets ecological immunology: understanding the links between organismal immunity and infection dynamics in natural populations. Functional Ecology 25, 48-60

Hay, K. B., Fredensborg, B. L. and Poulin, R. (2005). Trematodeinduced alterations in shell shape of the mud snail Zeacumantus subcarinatu (Prosobranchia : Batillariidae). Fournal of the Marine Biological Association of the United Kingdom 85, 989-992.

Hayden, M. J., Nguyen, T. M., Waterman, A., McMichael, G. L. and Chalmers, K. J. (2008). Application of multiplex-ready PCR for fluorescence-based SSR genotyping in barley and wheat. Molecular Breeding 21 , 271-281.

Hillyer, J. F., Schmidt, S. L., Fuchs, J.F., Boyle, J.P. and Christensen, B. M. (2005). Age-associated mortality in immune challenged mosquitoes (Aedes aegypti) correlates with a decrease in haemocyte numbers. Cellular Microbiology 7, 39-51.

Jiravanichpaisal, P., Lee, B. L. and Söderhäll, K. (2006). Cell-mediated immunity in arthropods: Hematopoiesis, coagulation, melanization and opsonization. Immunobiology 211, 213-236.

Keeney, D. B., Waters, J. M. and Poulin, R. (2006). Microsatellite loci for the New Zealand trematode Maritrema novaezealandensis. Molecula Ecology Notes 6, 1042-1044.

Koehler, A. V., Gonchar, A. G. and Poulin, R. (2011a). Genetic and environmental determinants of host use in the trematode Maritrema novaezealandensis (Microphallidae). Parasitology 138, 100-106.

Koehler, A. V. and Poulin, R. (2010). Host partitioning by parasites in an intertidal crustacean community. Fournal of Parasitology 96, 862-868. Koehler, A. V., Springer, Y. P., Keeney, D. B. and Poulin, R. (2011b) Intra- and inter-clonal phenotypic and genetic variability of the trematode
Maritrema novaezealandensis. Biological Fournal of the Linnean Society 103, 106-116.

Kostadinova, A. and Mavrodieva, R.S. (2005). Microphallids in Gammarus insensibilis Stock, 1966 from a Black Sea lagoon: host response to infection. Parasitology 131, 347-354.

Kraaijeveld, A. R., Limentani, E. C. and Godfray, H. C. J. (2001). Basis of the trade-off between parasitoid resistance and larval competitive ability in Drosophila melanogaster. Proceedings of the Royal Society of London, B 268 259-261.

Kurtz, J. (2002). Phagocytosis by invertebrate hemocytes: Causes of individual variation in Panorpa vulgaris scorpionflies. Microscopy Research and Technique 57, 456-468.

Lazzaro and Little, T. (2009). Immunity in a variable world. Philosophical Transactions of the Royal Society B: Biological Sciences 364, 15-26.

Le Moullac, G. and Haffner, P. (2000). Environmental factors affecting immune responses in Crustacea. Aquaculture 191, 121-131.

Lorenzon, S., de Guarrini, S., Smith, V. J. and Ferrero, E. A. (1999). Effects of LPS injection on circulating haemocytes in crustaceans in vivo. Fish \& Shellfish Immunology 9, 31-50.

Molecular Ecology Resources Primer Development Consortium (2009). Permanent genetic resources added to Molecular Ecology Resources database 1 January 2009-30 April 2009. Molecular Ecology Resources 9, 1375-1379.

Nappi, A. J. (1981). Cellular immune response of Drosophila melanogaster against Asobara tabida. Parasitology 83, 319-324

Paterson, S. (2005). No evidence for specificity between host and parasite genotypes in experimental Strongyloides ratti (Nematoda) infections. International Fournal for Parasitology 35, 1539-1545.

Persson, M., Cerenius, L. and Soderhall, K. (1987). The influence of haemocyte number on the resistance of the freshwater crayfish, Pacifastacus leniusculus Dana, to the parasitic fungus Aphanomyces astaci. Fournal of Fish Diseases 10, 471-477.

Poulin, R. (2001). Interactions between species and the structure of helminth communities. Parasitology 122 (Suppl.) S3-11.

R Development Core Team. (2010). R: A Language and Environment for Statistical Computing. R Foundation for Statistical Computing, Vienna, Austria.

Rauch, G., Kalbe, M. and Reusch, T. B. H. (2006). One day is enough: rapid and specific host-parasite interactions in a stickleback-trematode system. Biology Letters 2, 382-384.

Read, A. and Viney, M. (1996). Helminth immunogenetics: Why bother? Parasitology Today 12, 337-343.

Rigaud, T. and Moret, Y. (2003). Differential phenoloxidase activity between native and invasive gammarids infected by local acanthocephalans: differential immunosuppression? Parasitology 127, 571-577.

Rodriguez, J., Boulo, V., Mialhe, E. and Bachere, E. (1995). Characterisation of shrimp haemocytes and plasma components by monoclonal antibodies. Fournal of Cell Science 108, 1043-1050.

Rolff, J. and Siva-Jothy, M. T. (2003). Invertebrate ecological immunology. Science 301, 472-475

Sadd, B. M. and Schmid-Hempel, P. (2009). Principles of ecological immunology. Evolutionary Applications 2, 113-121.

Schmid-Hempel, P. and Ebert, D. (2003). On the evolutionary ecology of specific immune defence. Trends in Ecology \& Evolution 18, 27-32.

Scholtz, G., Braband, A., Tolley, L., Reimann, A., Mittmann, B., Lukhaup, C., Steuerwald, F. and Vogt, G. (2003). Ecology: Parthenogenesis in an outsider crayfish. Nature, London 421, 806-806. Schuelke, M. (2000). An economic method for the fluorescent labeling of PCR fragments. Nature Biotechnology 18, 233-234.

Seppälä, O., Karvonen, A. and Valtonen, E. T. (2007). Phenotypic variation in infectivity of Diplostomum spathaceum cercariae within a population. Fournal of Parasitology 93, 1244-1246.

Seppälä, O., Karvonen, A., Valtonen, E. T. and Jokela, J. (2009). Interactions among co-infecting parasite species: a mechanism maintaining genetic variation in parasites? Proceedings of the Royal Society of London, $B$ 276, 691-697.

Sequeira, T., Tavares, D. and Arala-Chaves, M. R. (1996). Evidence for circulating hemocyte proliferation in the shrimp Penaeus japonicus. Developmental \& $^{\circ}$ Comparative Immunology 20, 97-104

Sicard, M., Chevalier, F., De Vlechouver, M., Bouchon, D., Greve, P. and Braquart-Varnier, C. (2010). Variations of immune parameters in terrestrial isopods: a matter of gender, aging and Wolbachia. Naturwissenschaften $\mathbf{9 7}, 819-826$

Söderhäll, I., Bangyeekhum, E., Mayo, S. and Söderhäll, K. (2003). Hemocyte production and maturation in an invertebrate animal; proliferation and gene expression in hematopoietic stem cells of Pacifastacus leniusculus. Developmental and Comparative Immunology 27, 661-672. 
Söderhäll, K. and Cerenius, L. (1998). Role of the prophenoloxidaseactivating system in invertebrate immunity. Current Opinion in Immunology 10, 23-28.

Thomas, F., Guldner, E. and Renaud, F. (2000). Differential parasite (Trematoda) encapsulation in Gammarus aequicauda (Amphipoda). The Fournal of Parasitology 86, 650-654.

Thomas, F., Renaud, F., Rousset, F., Cezilly, F. and de Meeûs, T. (1995). Differential mortality of two closely related host species induced by one parasite. Proceedings of the Royal Society of London, B 260, 349-352.
Thomas, M. B., Watson, E. L. and Valverde-Garcia, P. (2003). Mixed infections and insect-pathogen interactions. Ecology Letters 6, 183188.

Vardo-Zalik, A. M. (2009). Clonal diversity of a malaria parasite, Plasmodium mexicanum, and its transmission success from its vertebrateto-insect host. International fournal for Parasitology 39, 1573-1579.

Walsh, P. S., Metzger, D. A. and Higuchi, R. (1991). Chelex 100 as a medium for simple extraction of DNA for PCR-based typing from forensic material. BioTechniques 10, 506-513. 
APPENDIX 1. Microsatellite primers for Maritrema novaezealandensis

(Forward primers have M13(-21) tag and reverse primers have a GTTTCTT pigtail. Four fluorescent dyes and four size classes of PCR segments were used to multiplex the sequencing reactions into two 96 -well plates. *Indicates original primer was altered to fit size restrictions.)

\begin{tabular}{|c|c|c|c|c|c|}
\hline Plate & Dye & Size & Marker & Primer sequences $\left(5^{\prime}\right.$ to $\left.3^{\prime}\right)$ & Annealing temp. ${ }^{\circ} \mathrm{C}$ \\
\hline \multirow[t]{16}{*}{1} & FAM & Small & flMno45F & TGTAAAACGACGGCCAGTGATACTCTACGTGAGCCTCGC & 50 \\
\hline & & Large & flMar111 F & TGTAAAACGACGGCCAGTTGGCGCTTACCTCCAACAC & 50 \\
\hline & & & flMar111R & GTTTCTTACTGAAAGAGCCGGTTGTC & \\
\hline & NED & Med* & flMar80F & TGTAAAACGACGGCCAGTAGAGTGGACGGCATTTTGTC & 50 \\
\hline & & & flMar80R & GTTTCTTCATGCGCAAGAATGTATTGG & \\
\hline & PET & Small* & flMar42F & TGTAAAACGACGGCCAGTATCAAAGCTCTTTCAAGTCATGT & 50 \\
\hline & & & flMar42R & GTTTCTTGTGATACCGAGCACCACACA & \\
\hline & & Large & flMar64F & TGTAAAACGACGGCCAGTTCATAACGGCGTACCCACC & 50 \\
\hline & & & flMar64R & GTTTCTTACCGGGAGAATCCTTGTGC & \\
\hline & VIC & Small* & flMar156F & TGTAAAACGACGGCCAGTGGTCGCAGTCAGGACAGAAT & 50 \\
\hline & & & flMar156R & GTTTCTTCTGCTTGATCGTCAAAGTGG & \\
\hline & & Med & flMar19F & TGTAAAACGACGGCCAGTTCCCTCTCGCTTCTTACGC & 50 \\
\hline & & & flMar19R & GTTTCTTGGTGGGTCGTAATAGCCAATC & \\
\hline & & Large & flMar70F & TGTAAAACGACGGCCAGTCTGTCAATTCCTTGAGCCCG & 50 \\
\hline & & & flMar70R & GTTTCTTTCGTCCCAATTCGACTCTTG & \\
\hline & & $\mathrm{XL}$ & $\begin{array}{l}\text { flMar34F } \\
\text { flMar34R }\end{array}$ & $\begin{array}{l}\text { TGTAAAACGACGGCCAGTCGTCGTTCTGATCTTGGCTG } \\
\text { GTTTCTTAGACGATGGGGTGACCTTC }\end{array}$ & 50 \\
\hline \multirow[t]{22}{*}{2} & FAM & Small & flMar107F & TGTAAAACGACGGCCAGTGGAAGCAGATCATAAAATTCACAAGC & 50 \\
\hline & & & flMar107R & GTTTCTTGGCCTTGGACGGATTTGAC & \\
\hline & & Med & flMar74F & TGTAAAACGACGGCCAGTGTGCATTCATTGGTTGAACAGG & 50 \\
\hline & & & flMar74R & GTTTCTTATAAGTGGGGTGAGCTGCG & \\
\hline & & $\mathrm{XL}$ & flMar13F & TGTAAAACGACGGCCAGTATACCCTTCGCCCTTCGTC & 58 \\
\hline & & & flMar13R & GTTTCTTGGCAACCCTTCGTGTTGTG & \\
\hline & NED & Small & flMno6F & TGTAAAACGACGGCCAGTTCAATGCCTTATGTGCCACCG & 66 \\
\hline & & & flMno6R & GTTTCTTGCCCAACCCAACTCTCAACG & \\
\hline & & Large & flMar125F & TGTAAAACGACGGCCAGTCGGGTCTTCTTCCGGGG & 50 \\
\hline & & & flMar125R & GTTTCTTGCAATATCCGTCGCCTAGC & \\
\hline & PET & Small & flMno $28 \mathrm{~F}$ & TGTAAAACGACGGCCAGTGATGGGTGCGAATATCACAG & 50 \\
\hline & & & flMno28R & GTTTCTTATTACTCTGAACGGTACTCCG & \\
\hline & & Large & flMar39F & TGTAAAACGACGGCCAGTTTGGAGCGCTAATGGACTG & 50 \\
\hline & & & flMar39R & GTTTCTTACAGGAGAAGTGACCACGG & \\
\hline & $\mathrm{VIC}$ & Small & flMno47F & TGTAAAACGACGGCCAGTCGTGGAACGAGCAGACATC & 50 \\
\hline & & & flMno47R & GTTTCTTGGGAGCATTCTAAGGGGAA & \\
\hline & & Med & flMar102F & TGTAAAACGACGGCCAGTACAACAGGGGCACTTGACG & 50 \\
\hline & & & flMar102R & GTTTCTTCCCATCATATCACTCATGCTTACC & \\
\hline & & Large & flMar22F & TGTAAAACGACGGCCAGTCGTCCACTGTTCGAGGTTG & 50 \\
\hline & & & flMar22R & GTTTCTTGTCCACTGAAACACACTCGTC & \\
\hline & & $\mathrm{XL} *$ & flMar88F & TGTAAAACGACGGCCAGTTCGGCTGATAGTTGAAGACG & 50 \\
\hline & & & flMar88R & GTTTCTTCCTCAAGGTTGGATTCTTGG & \\
\hline
\end{tabular}

